\title{
The Role of Second Phase Intermetallic Particles on the Spall Failure of 5083 Aluminum
}

\author{
C. L. Williams ${ }^{1}$ - T. Sano ${ }^{1}$ T. R. Walter ${ }^{1} \cdot$ J. Bradley $^{2}$ L. J. Kecskes ${ }^{1}$
}

Received: 15 September 2016/Accepted: 13 October 2016/Published online: 20 October 2016

(C) Society for Experimental Mechanics, Inc (outside the US) 2016

\begin{abstract}
5083 aluminum alloy is a light-weight and strain-hardened material used in high strain-rate applications such as those experienced under shock loading. Symmetric real-time (in situ) and end-state (ex situ recovery) plate impact shock experiments were conducted to study the spall response and the effects of microstructure on the spall properties of both 5083-H321 and 5083-ECAE $+30 \%$ cold-rolled (CR) aluminum alloys shock loaded to approximately $1.46 \mathrm{GPa}(\sim 0.2 \mathrm{~km} / \mathrm{s})$ and $2.96 \mathrm{GPa}(\sim 0.4 \mathrm{~km} / \mathrm{s})$. The results show that mechanically processing the 5083-H321 aluminum by Equal Channel Angular Extrusion (ECAE), followed by subsequent CR significantly increases the Hugoniot Elastic Limit (HEL) by $78 \%$. However, this significant increase in HEL was at the expense of spall strength. The spall strength of the 5083 -ECAE $+30 \%$ CR aluminum dropped by 37 and $23 \%$ when compared to their 5083-H321 aluminum counterpart at shock stresses of approximately 1.46 and $2.96 \mathrm{GPa}$ respectively. This reduction in spall strength is
\end{abstract}

\footnotetext{
C. L. Williams

cyril.1.williams.civ@mail.mil

T. Sano

tomoko.sano.civ@mail.mil

T. R. Walter

timothy.r.walter3.civ@mail.mil

J. Bradley

jermaine.m.bradley.ctr@mail.mil

L. J. Kecskes

laszlo.j.kecskes.civ@mail.mil
}

1 U. S. Army Research Laboratory, Aberdeen Proving Ground, Aberdeen, MD, USA

2 Survice Engineering Company, Aberdeen Proving Ground, Aberdeen, MD, USA attributed to the cracking and re-alignment of the manganese $(\mathrm{Mn})$-iron $(\mathrm{Fe})$ rich second phase intermetallic particles during mechanical processing (i.e., ECAE and subsequent $\mathrm{CR}$ ), which are consequently favorable to spallation.

Keywords Shock · Spall - Inclusions · Microstructure · Intermetallic $\cdot$ Failure

\section{Introduction}

5083 aluminum is a light-weight, strain-hardened, corrosion resistant, and high strength alloy commonly used in high strain-rate applications such as those experienced under shock loading. The chemical composition of the alloy is $4.0-4.9 \mathrm{wt} \%$ magnesium (Mg), $0.4-1.0 \mathrm{wt} \%$ manganese $(\mathrm{Mn})$, and the remainder being aluminum in addition to trace elements. 5083 aluminum is not a heat treatable alloy but significant strengthening effects can be achieved through alloying with $\mathrm{Mg}$ and $\mathrm{Mn}$ followed by mechanical processing such as cold working. Magnesium is added for solid solution strengthening and manganese for refining the grain structure through the formation of dispersoid particles, which pin grain boundaries.

The spall response of mechanically processed 5083 aluminum (i.e., cold and hot rolled, extruded, etc.) has been previously studied by several researchers [1-4]. Results from the work of Boteler and Dandekar [1] show no spall strength dependency on peak shock stress ranging from 1.58 to $2.78 \mathrm{GPa}$ for $5083-\mathrm{H} 131$ aluminum. ApplebyThomas and Hazell [2] were able to show that 5083-H32 armor grade aluminum exhibited no strengthening effects as a function of peak shock stress. From microstructural analyses conducted on shock recovered samples, they 
determined that spall failure in 5083-H32 aluminum initiated and propagated from one inclusion to another [2]. Whelchel et al. [3] studied the spall behavior of 5083-H116 aluminum and found that the Hugoniot Elastic Limit (HEL) in the transverse direction exhibited the highest value and the lowest HEL was observed along the rolling direction. In addition, they determined that the spall strength in the rolling direction was higher than that in the transverse direction and from microstructural studies, they determined that spall damage propagated along grain boundaries.

In addition to studying the spall behavior of 5083-H116 aluminum, Whelchel et al. [4] also studied the spall behavior of 5083-H321 aluminum, which was mechanically processed using Equal-Channel Angular Extrusion (ECAE), and then rolled to yield a uniform grain structure throughout the plate. This processing technique produced an Ultra Fine Grain (UFG) structure with an average grain size of approximately $400 \mathrm{~nm}$. From this research work, they showed that samples mechanically processed using ECAE alone did not produce alignment of the second phase intermetallic particles favorable to spall failure and therefore, increases in spall strength and HEL were observed with minor orientation dependence. However, when the ECAE material was further rolled, the second phase intermetallic particles were re-aligned preferentially along grain boundaries and this re-alignment further weaken an already weak grain boundary; this realignment is favorable to spall failure. Subsequently rolling the material results in significant increases in HEL but considerable decreases in the spall strength [4]. The objective of this research is to further develop a better understanding of the microstructural aspects of spall failure, in particular the role of second phase intermetallic particles in 5083-H321 aluminum which has been mechanically processed using ECAE then $\mathrm{CR}$ and shock loaded to various stresses. This objective is achieved by studying the spall response using real-time (in situ) plate impact shock experiments and the acquired results are augmented by end-state (ex situ recovery) plate impact shock experiments.

\section{Materials and Experimental Methods}

\section{Materials}

The as-received rolled 5083-H321 aluminum plate was mechanically processed using the ECAE $4 \mathrm{E}$ route at $250{ }^{\circ} \mathrm{C}$. After each pass through the die, the 5083-H321 aluminum plate was rotated $90^{\circ}$ about the through-thickness normal of the plate for a total of four passes. The resulting ECAE plate was further cold-rolled (CR) at room temperature to $30 \%$ reduction in thickness. By employing ECAE processing and subsequent $30 \%$ cold rolling, the microstructure throughout the 5083-H321 aluminum plate was transformed to a uniform highly refined grain structure with an average grain size of approximately $400 \mathrm{~nm}$ [5]. Whelchel et al. [4] have previously determined that the microstructure developed after four passes reveal large inclusions and after cold rolling, the inclusions were broken into smaller particles, which eventually aligned themselves along grain boundaries. It is noteworthy to point out that the 5083 aluminum plate used for this research is identical to that used by Whelchel et al. [4].

The residual microstructure acquired using Scanning Electron Microscope (SEM) of the as-received 5083-H321 and 5083-ECAE $+30 \% \mathrm{CR}$ aluminum plates are shown in Fig. 1. The residual microstructures of both materials were acquired from the mid-section of both plates. The micrographs in Fig. 1 show that thick clusters of second phase intermetallic particles (shown as white in the figure) in the asreceived 5083-H321 aluminum (Fig. 1a) become thinner after ECAE processing plus subsequent $30 \%$ cold rolling (Fig. 1b). All plate impact samples were cut through the thickness of the $5083 \mathrm{ECAE}+30 \% \mathrm{CR}$ aluminum plate using wire Electro-Discharge Machining (EDM). The average specimen dimensions were $42.950 \pm 0.044 \mathrm{~mm}$ in diameter and $6.044 \pm 0.047 \mathrm{~mm}$ thick. The measured density $(\rho)$ was determined to be $2691.453 \pm 57.245 \mathrm{~kg} / \mathrm{m}^{3}$. The longitudinal $\left(C_{\mathrm{L}}\right)$ and shear wave $\left(C_{\mathrm{S}}\right)$ speeds were measured to be $6.394 \pm 0.040 \mathrm{~km} / \mathrm{s}$ and $3.162 \pm 0.022 \mathrm{~km} / \mathrm{s}$ respectively, and the calculated elastic properties were; elastic modulus $(E)$ : $72.023 \pm 1.229 \mathrm{GPa}$, shear modulus $(G)$ : $26.913 \pm 0.469 \mathrm{GPa}$, bulk modulus $(K): 74.141 \pm$ $1.592 \mathrm{GPa}$, Lame's constant $(\lambda): 56.199 \pm 1.423 \mathrm{GPa}$, and Poisson's ratio $(v)$ : $0.338 \pm 0.003$. The bulk sound speed $\left(C_{\mathrm{O}}\right)$ was computed using the bulk modulus to be $5.249 \pm$ $0.041 \mathrm{~km} / \mathrm{s}$. These properties are consistent with those reported in the open literature [1-5].

\section{Plate Impact Experiments}

A total of eight shock experiments were conducted for this investigation using a single stage $102 \mathrm{~mm}$ (slotted bore) diameter gas gun at the shock physics laboratory, US Army Research Laboratory (ARL), Aberdeen Proving Ground (APG). Four real-time (in situ) shock experiments were conducted to study the spall responses of both $5083-\mathrm{H} 321$ and 5083-ECAE $+30 \% \mathrm{CR}$ aluminum at velocities of approximately 0.2 and $0.4 \mathrm{~km} / \mathrm{s}$ respectively. The free surface velocity-time histories for all real-time experiments were acquired using Velocity Interferometry System for Any Reflector (VISAR) [6]. In addition, four end-state (ex situ spall recovery) experiments were conducted to augment all four real-time shock experiments in order to study the effects of microstructure on the spall properties of both materials. All eight experiments were symmetric, 

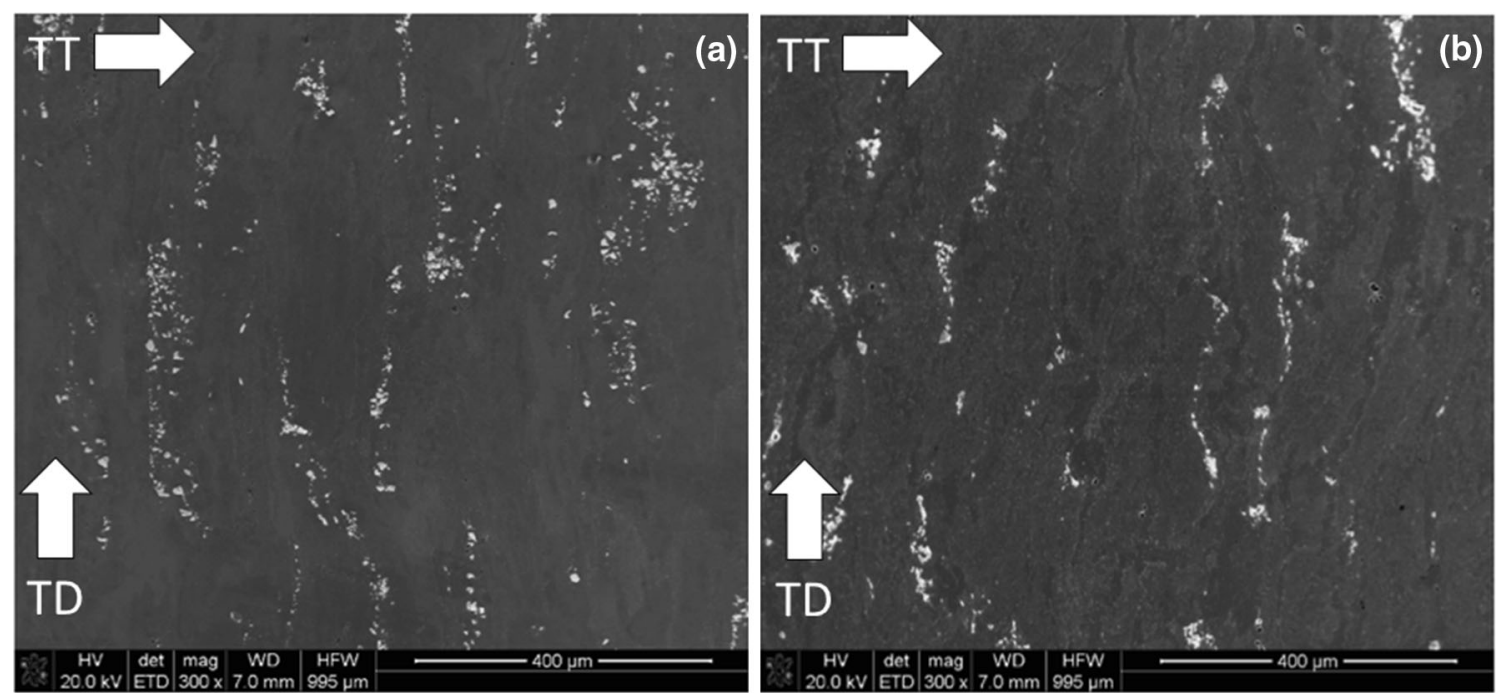

Fig. 1 SEM micrographs of the residual microstructure of a as-received 5083-H321 aluminum and b 5083-ECAE $+30 \%$ CR aluminum. TT and TD indicate through-thickness and transverse directions respectively

implying that both the flyer and sample materials were identical (same impedance). A spall plate and momentum trapping rings were used in all end-state experiments to mitigate rogue radial release waves. The basic loading configuration and procedure for both real-time and endstate shock experiments have been previously described by Williams et al. [7-9].

\section{Results and Discussion}

Figure 2 shows the free surface velocity-time histories of 5083-H321 aluminum shocked to average velocities of $0.203 \mathrm{~km} / \mathrm{s}$, corresponding to $1.45 \mathrm{GPa}$ peak shock stress and $0.394 \mathrm{~km} / \mathrm{s}$, corresponding to $2.88 \mathrm{GPa}$ peak shock stress respectively. Both velocity profiles are characteristic

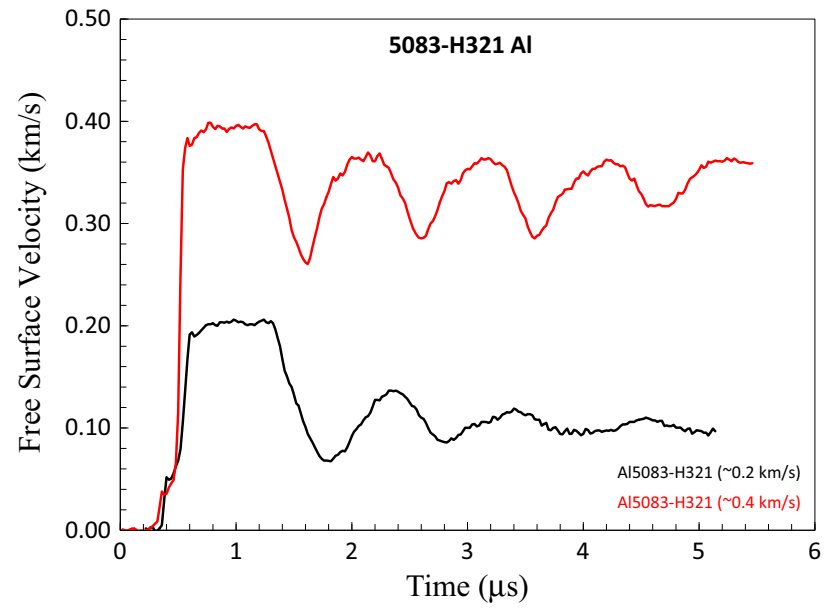

Fig. 2 Free surface velocity profiles for 5083-H321 aluminum at approximately 0.2 and $0.4 \mathrm{~km} / \mathrm{s}$, respectively of the spall response for metals and metallic alloys. In that, sequentially, they exhibit a HEL, short shock rise-time (jump), stable Hugoniot state (shock state), elastic-plastic release, spall, and reverberations about the spall plane. Similarly, the velocity-time histories of 5083ECAE $+30 \% \mathrm{CR}$ aluminum shocked to average velocities of $0.196 \mathrm{~km} / \mathrm{s}$, corresponding to $1.40 \mathrm{GPa}$ peak shock stress and $0.395 \mathrm{~km} / \mathrm{s}$, corresponding to $2.89 \mathrm{GPa}$ peak shock stress respectively are shown in Fig. 3. However, the velocity profile for the 5083-ECAE $+30 \% \mathrm{CR}$ aluminum shocked to $1.40 \mathrm{GPa}$ is not a characteristic spall signal of metals and metallic alloys. The velocity profile beyond the elastic-plastic release phase (beyond $\sim 1.5 \mu \mathrm{s}$ ) is distinctly different from the other profiles and it is indicative of incipient spall. The spall process initiated but was soon arrested due to insufficient stress required to drive the spall

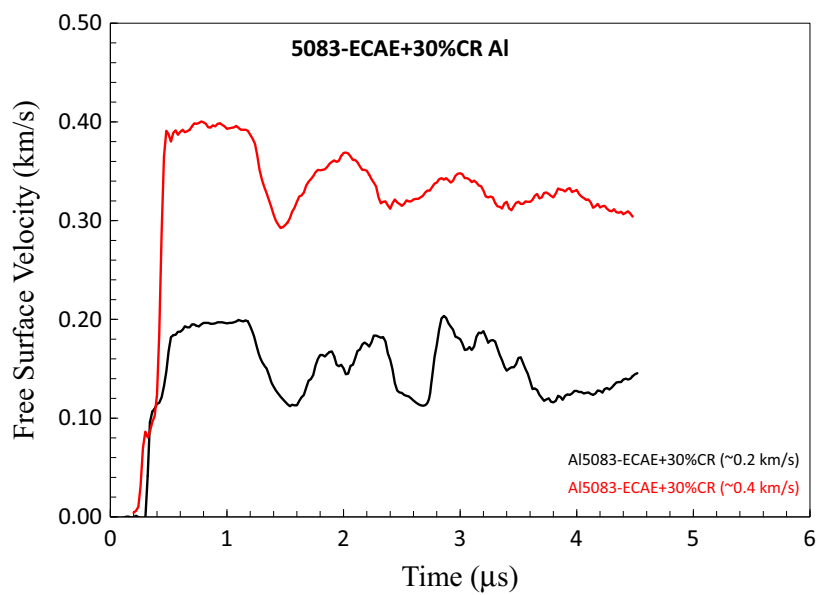

Fig. 3 Free surface velocity profiles for 5083-ECAE $+30 \% \mathrm{CR}$ aluminum at approximately 0.2 and $0.4 \mathrm{~km} / \mathrm{s}$, respectively 
process to completion. A comparison between the HEL and uncorrected spall strength (not corrected for elastic-plastic effects) of both 5083-H321 and 5083-ECAE + 30\% CR aluminum acquired at approximately 0.2 and $0.4 \mathrm{~km} / \mathrm{s}$ are shown in Fig. 4. Note that the HEL and uncorrected spall strength are reported in this paper for comparison purposes and were computed in accordance with Eqs. (1) [10] and (2) [11] respectively,

$\sigma_{\mathrm{HEL}}=\frac{1}{2} \rho_{\mathrm{o}} C_{\mathrm{L}} U_{\mathrm{fs}}$

$\sigma^{*}=\frac{1}{2} \rho_{\mathrm{o}} C_{\mathrm{o}} \Delta U_{\mathrm{fs}}$

where $\rho_{\mathrm{o}}$ is the initial density, $C_{\mathrm{L}}$ is the longitudinal velocity, $C_{\mathrm{o}}$ is the bulk sound speed, $U_{\mathrm{fs}}$ is the free surface velocity, and $\Delta U_{\mathrm{fs}}$ is the pullback velocity. On one hand, the HELs of the 5083-H321 aluminum were determined to be approximately 0.435 and $0.409 \mathrm{GPa}$ at peak shock stresses of 1.45 and $2.88 \mathrm{GPa}$, respectively. The uncorrected spall strengths for the same material were determined to be 0.947 and $0.938 \mathrm{GPa}$ at the same peak shock stresses, respectively. This represents a $1 \%$ change (insignificant) in spall strength between 1.45 and $2.88 \mathrm{GPa}$ peak shock stress.

The HELs of the 5083-ECAE + $30 \%$ CR aluminum were determined to be 0.774 and $0.731 \mathrm{GPa}$ at peak shock stresses of 1.40 and $2.89 \mathrm{GPa}$, respectively. The corresponding uncorrected spall strengths were determined to be 0.601 and $0.719 \mathrm{GPa}$, respectively, for the same peak shock stresses. Increasing the peak shock stress from 1.40 and $2.89 \mathrm{GPa}$ produces a $20 \%$ increase in spall strength (uncorrected) of the 5083$\mathrm{ECAE}+30 \% \mathrm{CR}$ aluminum. The results in Fig. 4 also show that by mechanically processing the 5083-H321

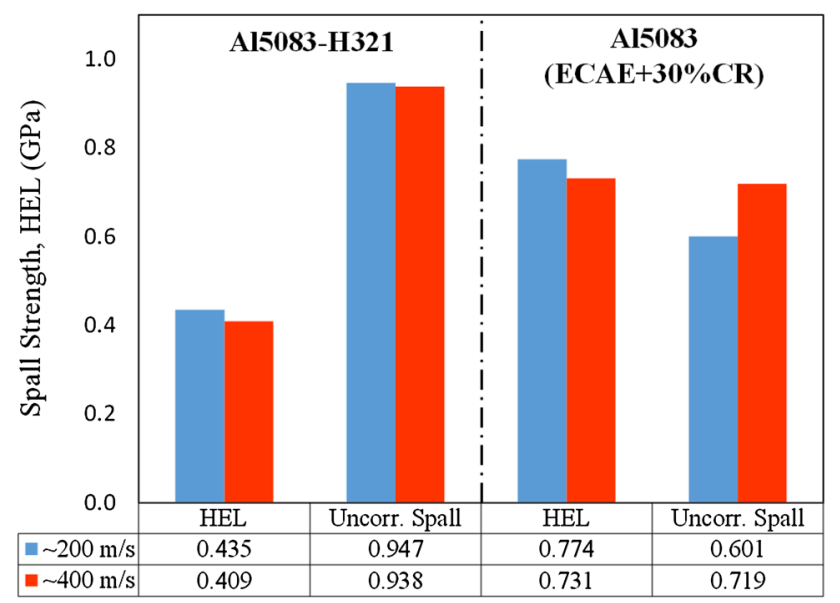

Fig. 4 Comparison between HEL and uncorrected spall strength of both 5083-H321 (left) and 5083-ECAE + $30 \%$ CR (right) aluminum acquired at approximately 0.2 and $0.4 \mathrm{~km} / \mathrm{s}$ using ECAE and $30 \% \mathrm{CR}$, the average $\mathrm{HEL}$ increases from $0.422 \pm 0.018$ to $0.753 \pm 0.030 \mathrm{GPa}$ representing a $78 \%$ increase. This increase in HEL is attributed to grain refinement through recrystallization resulting from the ECAE process [4] and also, to the increase in dislocation density resulting from cold rolling [9]. This is clearly evident from Eqs. (3) [12] and (4) [13], as the dislocation density increases, the preshock yield stress and HEL will increase respectively,

$\sigma_{\mathrm{o}}=\alpha \mu b \sqrt{\rho}$

$\sigma_{\mathrm{HEL}}=\frac{(1-v)}{(1-2 v)} \sigma_{\mathrm{o}}$

where $\sigma_{\mathrm{o}}$ is the preshock yield stress, $\alpha$ is a constant $\sim 0.5$, $\mu$ is the shear modulus, $b$ is the magnitude of the Burgers vector, $\rho$ is the dislocation density, $\sigma_{\mathrm{HEL}}$ is the HEL, and $v$ is the Poisson's ratio. However, the same is not true for the spall strength; mechanically processing the 5083-H321 aluminum using ECAE and CR to $30 \%$ reduction in thickness reduces the corresponding spall strengths acquired at approximately 0.2 and $0.4 \mathrm{~km} / \mathrm{s}$ by 37 and $23 \%$, respectively. This is perhaps due to the migration and eventual realignment of second phase intermetallic particles along grain boundaries during the ECAE and rolling processes. These particles serve as potential void nucleation sites during the spall process, and are consequently detrimental to the spall strength of the 5083-ECAE $+30 \% \mathrm{CR}$ aluminum as shown in Fig. 4 from in situ spall experiments. The real-time (in situ) shock experimental results discussed here are consistent with those reported by Whelchel et al. [4].

Results from ex situ spall recovery experiments conducted at peak shock stresses of approximately $1.46 \mathrm{GPa}$ for 5083-H321 aluminum and 5083-ECAE + 30\% CR aluminum are shown in Figs. 5 and 6, respectively. Although the velocity-time history shown in Fig. 2 for 5083-H321 aluminum shocked to approximately $1.46 \mathrm{GPa}$ $(\sim 0.2 \mathrm{~km} / \mathrm{s})$ is characteristic of spallation, the recovered sample did not reveal complete separation of the spalled sample. Nevertheless, X-ray micro-computed tomography (X-ray microCT) revealed a localized spall plane in the interior of the material as shown in Fig. 5a. Spallation was also revealed in the interior of the material after the sample was sectioned for microstructural analysis. The SEM micrograph shown in Fig. 5b represents the residual microstructure in the vicinity of the spall plane of the 5083-H321 aluminum shocked to approximately $1.46 \mathrm{GPa}$. The mid-section of the micrograph shows nucleated voids, which appear to have grown and coalesced with each other to form, isolated cracks along an approximate direction normal to the shock stress (depicted by a white arrow marked SD in Fig. 5b). The micrograph also reveals 

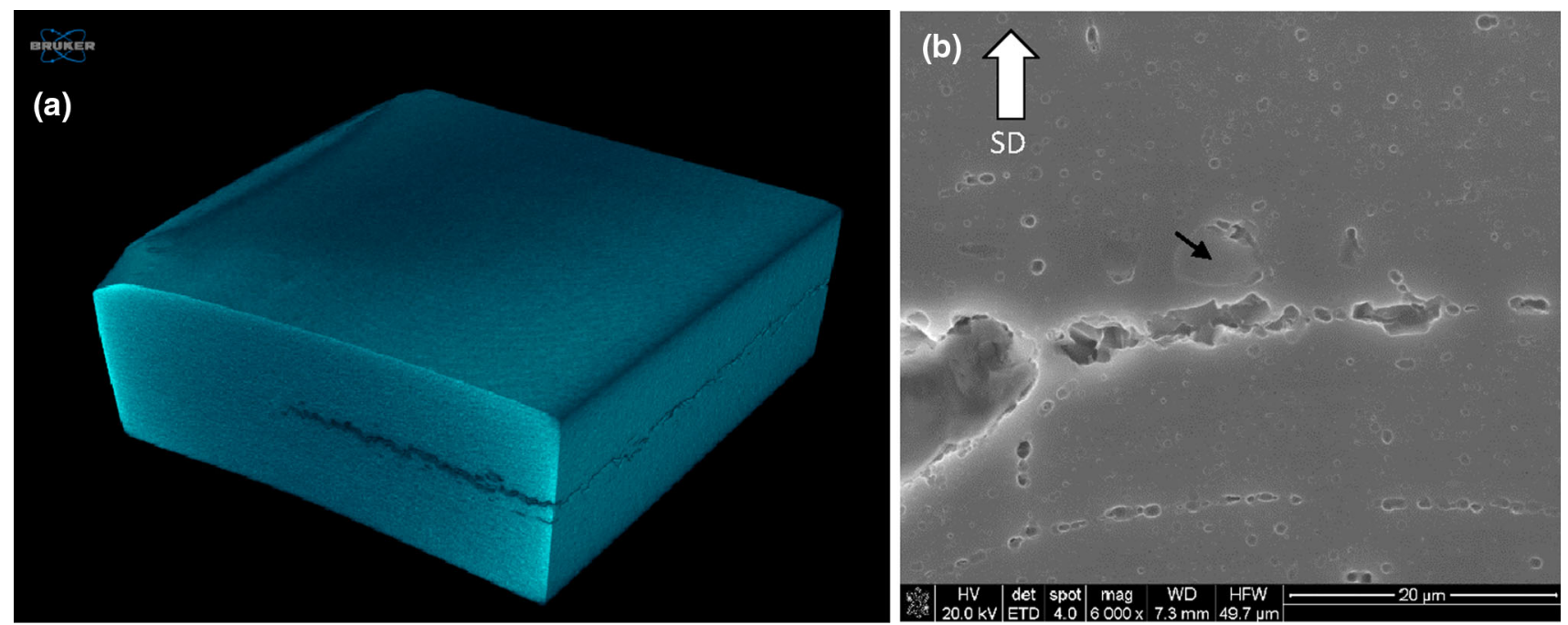

Fig. 5 The a X-ray microCT scan and b SEM residual microstructure of soft recovered 5083-H321 aluminum sample shocked at approximately 1.46 GPa. SD indicates shock direction and black arrow identifies a second phase intermetallic particle
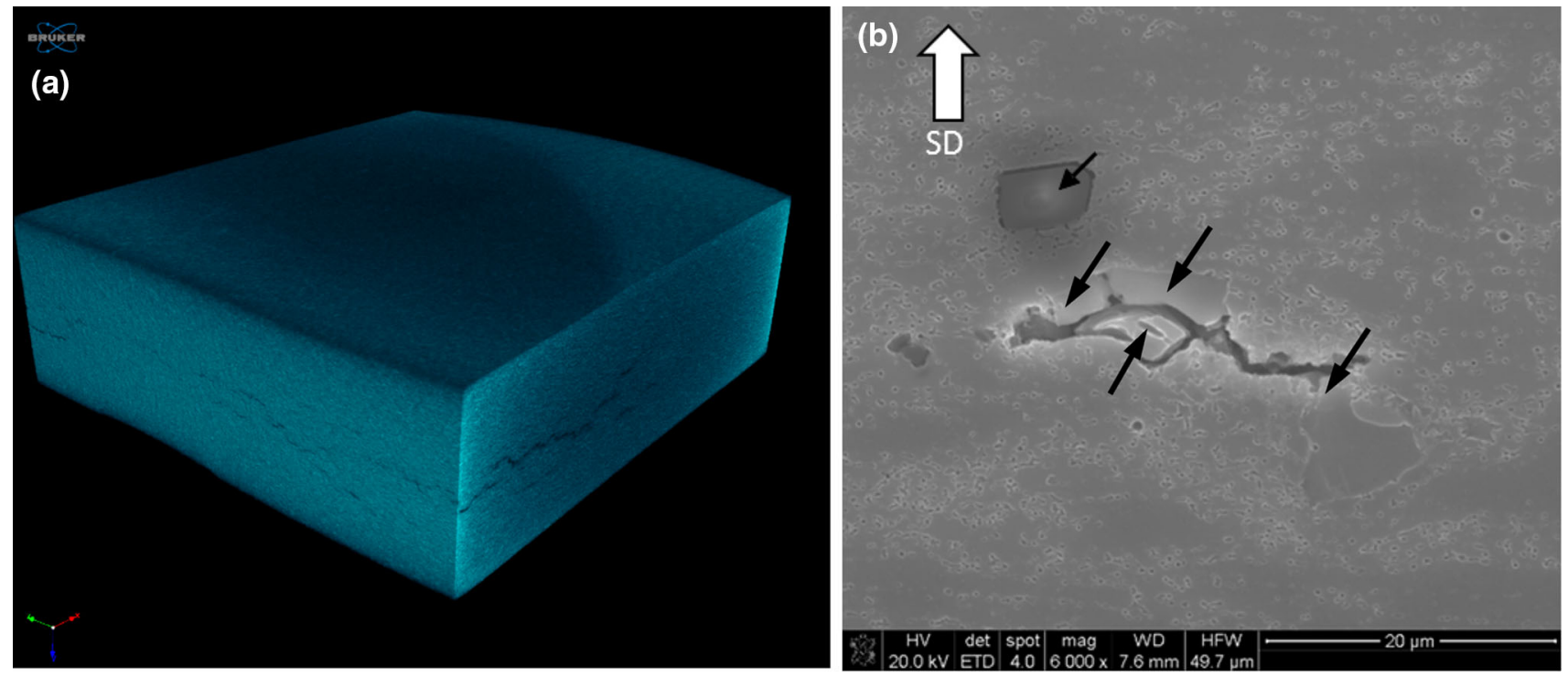

Fig. 6 The a X-ray microCT scan and b SEM residual microstructure of soft recovered 5083-ECAE + $30 \%$ CR aluminum sample shocked at approximately $1.46 \mathrm{GPa}$. SD indicates shock direction and black arrows identify second phase intermetallic particles

ligaments between cracks and a second phase intermetallic particle (identified by black arrow) above the crack with an average diameter of approximately $8 \mu \mathrm{m}$ (larger than the grain size of $\sim 400 \mathrm{~nm}$ ). In general, for the 5083-H321 aluminum, these second phase intermetallic particles were not commonly observed within cracks. These second phase inter-metallic particles were determined to be rich in manganese $(\mathrm{Mn})$ and iron $(\mathrm{Fe})$ by energy dispersive X-ray spectroscopy (EDS).

The X-ray microCT scan and SEM micrograph of the 5083-ECAE $+30 \%$ CR aluminum shock loaded to approximately $1.46 \mathrm{GPa}$ are shown in Fig. 6 . The 5083-ECAE $+30 \%$ CR aluminum show similar results to that of 5083-H321 aluminum, in that, the material spalled internally but did not separate into two halves as shown in the X-ray microCT scan in Fig. 6a. However, spallation in the interior of the 5083-H321 aluminum appears to be highly localized while that of the 5083-ECAE $+30 \%$ CR aluminum appears to meander across a wide damage zone consisting of multiple cracks. Unlike the 5083-H321 aluminum, numerous second phase intermetallic particles are visible within the crack opening strongly suggesting that the particles were potential void nucleation sites as shown in Fig. 6b. These particles were determined to be rich in $\mathrm{Mn}$ and Fe by EDS as shown in Fig. 7. The second phase intermetallic particles in Fig. $6 \mathrm{~b}$ appears to have been 
broken and partially de-bonded from the matrix aluminum possibly during the shock compression $[14,15]$. This debonding between the second phase intermetallic particle and matrix aluminum may serve as a potential void nucleation site during tensile loading [14-16]. It is noteworthy to point out that the numerous pits observed in the SEM micrographs are artifacts of chemical polishing.

To study the failure characteristics of 5083-H321 aluminum, a sample was shock loaded to $2.96 \mathrm{GPa}$ (corresponding to approximately $400 \mathrm{~m} / \mathrm{s}$ ) and soft recovered for microstructural characterization. The recovered sample completely spalled during the experiment and separated into two halves. Shown in Fig. 8 are fractographs of the spall surface and it reveals that the 5083-H321 aluminum sample exhibits a mixed-mode (brittle-ductile) failure. Figure 8a represents the general observation of different regions of the spall surface. As shown in the figure, some regions failed by ductile void nucleation, growth, and coalescence, whiles other regions by brittle-like fracture. A magnified view of a region that failed by ductile void nucleation, growth, and coalescence is shown in Fig. 8b. It is quite evident from the figure that second phase intermetallic particles, which were identified by EDS analysis, to be rich in $\mathrm{Mn}$ and $\mathrm{Fe}$ resides within void dimples. Similar observations were previously made in shock loaded AZ31B [16], AMX602 [17] magnesium alloys and other alloys $[14,15]$. Shown in Fig. $8 \mathrm{c}$ is a magnified view of a region that failed in a brittle mode exhibiting a rather complex surface that is smooth. Mixed-mode failure can occur when both homogeneous and heterogeneous nucleation of voids are triggered concurrently if the stress is high enough with homogeneous nucleation requiring the higher stress $[14,15]$. Low-angle grain boundaries, fine impurities and precipitates, dislocations tangles and networks, and vacancy clusters are potential homogeneous void nucleation sites $[14,15]$. On the other hand, high-angle grain boundaries, inclusions, and second-phase particles are potential heterogeneous void nucleation sites [14, 15]. Ductile fractures are generally a consequence of heterogeneous void nucleation as shown in Fig. 8b, at least at the micrometer length-scale. However, brittle-like fractures are generally a consequence of homogeneous void nucleation, shown in Fig. 8c. Higher magnification of these brittle-like fracture surfaces usually reveals nanovoids as a consequence of homogeneous void nucleation [8, 16, 17]. However, nanovoids were not observed in this case.

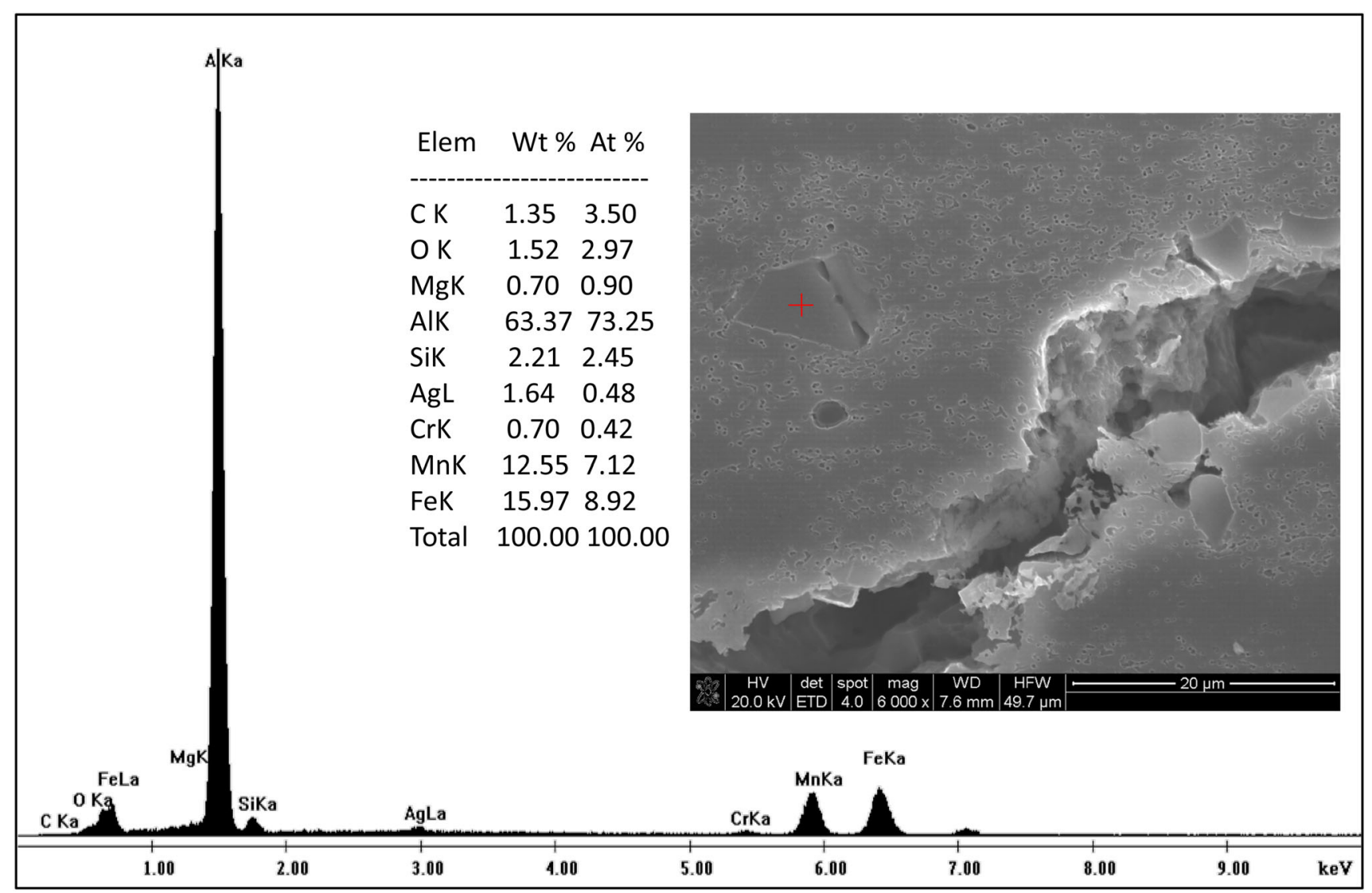

Fig. 7 EDS from the Mn-rich and Fe-rich particle (red-cross in the micrograph) of 5083-ECAE $+30 \%$ CR aluminum sample shocked at approximately $1.46 \mathrm{GPa}$ 


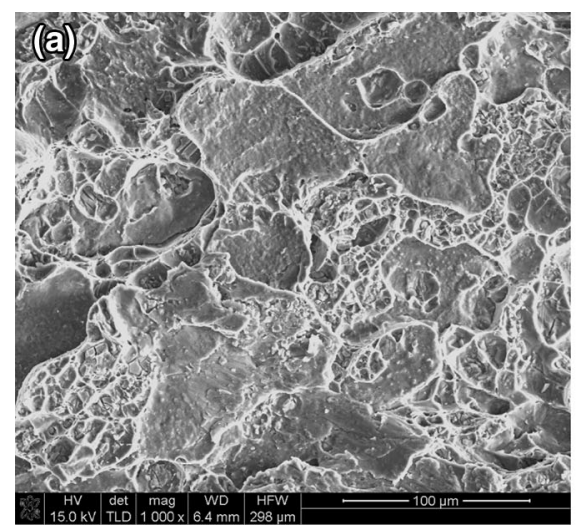

Fig. 8 SEM micrographs of the fracture surface of 5083-H321 aluminum sample shocked at approximately $2.96 \mathrm{GPa}$. a Areas consisting of dimples resulting from void nucleation and growth with isolated areas of brittle fracture. b Second phase Mn-Fe rich particles within the void dimples. c Smooth brittle-like surface
The X-ray microCT scan and SEM micrograph in Fig. 9 were obtained from the 5083-ECAE $+30 \%$ CR aluminum sample shock loaded to $2.96 \mathrm{GPa}$. Although the 5083-ECAE-30 \% CR aluminum sample appears to have totally spalled during the experiment, the spalled sample did not separate into two halves as shown in the X-ray microCT tomography scan in Fig. 9a. The SEM micrograph shown in Fig. $9 \mathrm{~b}$ reveals a large crack normal to the shock direction, formed as a consequence of the nucleation, growth, and coalescence of voids. Second phase intermetallic Mn-rich particles are visible along the crack length and are approximately $40 \mu \mathrm{m}$ apart from each other. Two of the particles (shown within the circular dashed line) appear to be locations were voids nucleated, then grew and coalesced to form cracks because of the curvature of the aluminum matrix surrounding the particles. The width of the crack between both circles is narrow, suggesting a potential location where the two voids coalesced. Also, numerous second phase intermetallic particles are revealed in the micrograph. However, these particles are farther away from the spall plane and therefore, were not able to grow and coalesce with neighboring particles. Almost all the inter-metallic particles outside the spall zone were de-bonded from the aluminum matrix. This observation is further evidence that particle-matrix de-bonding occurs during the shock compression phase and not during the tensile spall process. The micrograph also reveals ductile dimples within the interior of the crack resulting from void nucleation, growth, and coalescence.
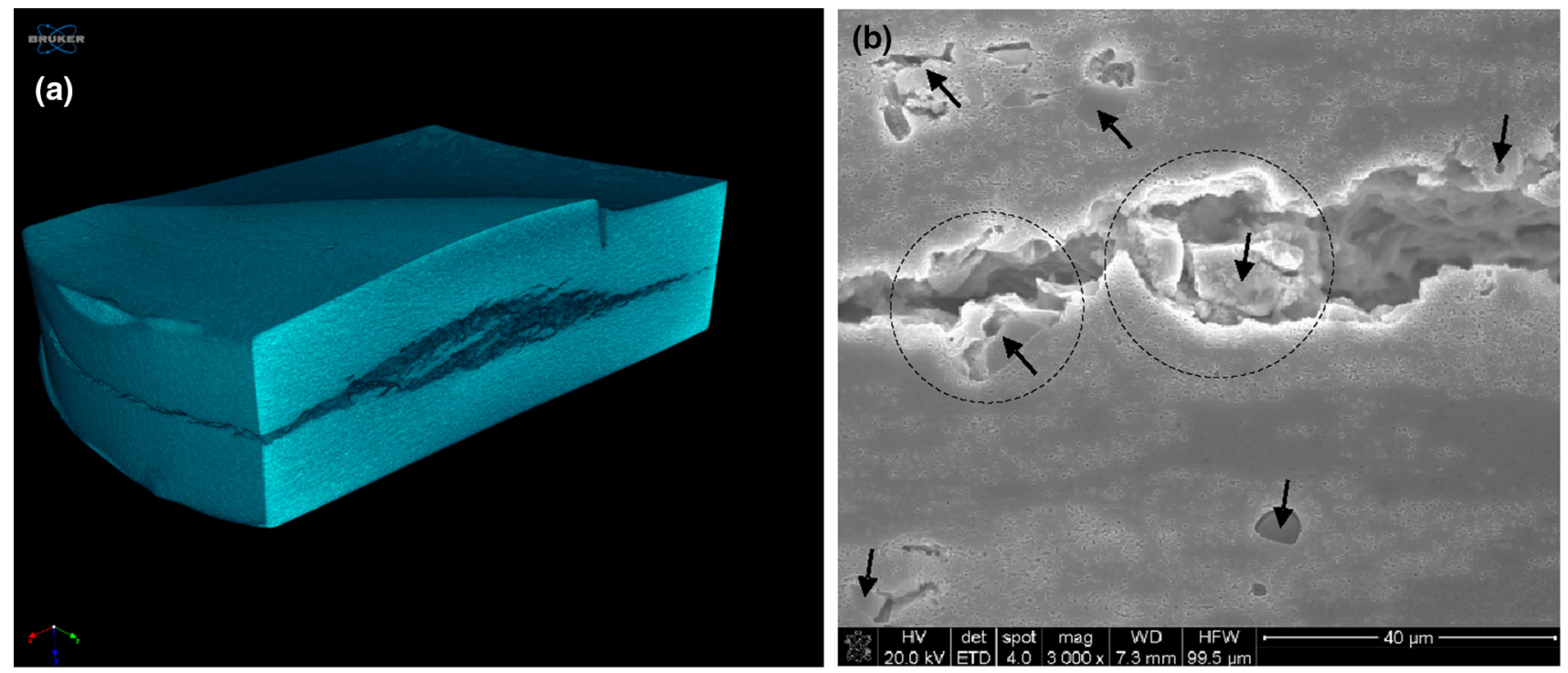

Fig. 9 The a X-ray microCT scan and b SEM residual microstructure of 5083-ECAE-30 \%CR aluminum sample shocked at approximately $2.96 \mathrm{GPa}$ 


\section{Conclusions}

As-received 5083-H321 aluminum plate was mechanically processed using ECAE and then CR to $30 \%$ reduction in thickness to achieve a highly refined ultra-fine grain structure through the thickness of the plate resulting in an average grain size of approximately $400 \mathrm{~nm}$. Plate impact specimens were machined from the through-thickness direction of the mechanically processed plate using wire EDM. Symmetric plate impact experiments were conducted on both 5083-H321 and 5083-ECAE + 30\% CR aluminum alloys. Real-time (in situ) and end-state (ex situ recovery) shock experiments were conducted to study the spall response and role of second phase inter-metallic particles on the spall properties of both 5083-H321 and 5083-ECAE $+30 \%$ CR aluminum alloys. The results from real-time plate impact experiments show that, by mechanically processing 5083-H321 aluminum using ECAE and then CR to $30 \%$ reduction in height, the average HEL increases by $78 \%$. However, this significant improvement on the dynamic yield strength under uniaxial strain conditions (HEL) was not realized for spallation. The spall results show no significant change in the spall strength of 5083-H321 aluminum shock loaded at 1.45 and $2.88 \mathrm{GPa}$ shock stress, respectively. However, the spall strength of the 5083-ECAE $+30 \%$ CR aluminum shock loaded at the same stress levels decreased by 37 and $23 \%$, respectively, when compared to their 5083-H321 aluminum counterpart.

End-state recovery experimental results show that the second phase intermetallic Mn-Fe rich particles de-bonded from the aluminum matrix during shock compression and were potential void nucleation sites in both materials. Furthermore, ex situ recovery results also show that spallation occur in both materials by void nucleation, growth, and coalescence. However, the overwhelming evidence show that spall failure occur along the re-aligned intermetallic Mn-Fe rich particles for the 5083-ECAE $+30 \%$ $\mathrm{CR}$ aluminum and this perhaps is responsible for the reduction in spall strength as a function of peak shock stress. On the other hand, the dominant failure characteristic for 5083-H321 aluminum was mixed-mode (ductilebrittle), emanating from homogeneous and heterogeneous nucleation of voids. More experimental investigations are needed to develop a better understanding of the microstructural aspects in particular the role of second phase intermetallic particles under shock compression and consequent failure of 5083 aluminum alloys.
Acknowledgments The authors are extremely grateful to Mr. Micah Gallagher for his valuable technical support, especially fabrication of the plate impact flyer and target. The U.S. Government is authorized to reproduce and distribute reprints for Government purposes notwithstanding any copyright notation herein. This article is approved for public release; distribution is unlimited.

\section{References}

1. Boteler JM, Dandekar DP (2006) Dynamic response of 5083-H131 aluminum alloy. J Appl Phys 100:054902

2. Appleby-Thomas GJ, Hazell PJ (2010) A study on the strength of an armour-grade aluminum under high strain-rate loading. J Appl Phys 107:123508

3. Whelchel RL, Kennedy GB, Dwivedi SK, Sanders TH Jr, Thadhani NN (2013) Spall behavior of rolled aluminum 5083-H116. J Appl Phys 113:233506

4. Whelchel RL, Thadhani NN, Sanders TH, Kecskes LJ, Williams CL (2014) Spall properties of Al5083 plate fabricated using equichannel angular pressing (ECAP) and rolling. J Phys Conf Ser 500(11): 112066

5. Jin H, Gallerneault M, Segal VM, Young PJ, Lloyd DJ (2011) Grain structure and texture in aluminum alloy AA5083 after equal angular channel extrusion, warm rolling and subsequent annealing. Mater Sci Technol 27:789-792

6. Barker LM, Hollenback RE (1972) Laser interferometry for measuring high velocities of any reflecting surface. J Appl Phys 43(11):4669

7. Williams CL, Ramesh KT, Dandekar DP (2012) The spall response of 1100-O aluminum. J Appl Phys 111(12):123528

8. Williams CL, Chen CQ, Ramesh KT, Dandekar DP (2014) On the shock stress, substructure evolution, and spall response of commercially pure1100-O aluminum. Mater Sci Eng A618:596-604

9. Williams CL, Chen CQ, Ramesh KT, Dandekar DP (2013) The effects of cold rolling on the microstructural and spall response of 1100 aluminum. J Appl Phys 114(9):093502

10. Antoun T, Seaman L, Curran DR, Kanel GI, Razorenov SV, Utkin AV (2003) Spall fracture. Springer, New York

11. Novikov SA, Divnov II, Ivanov AG (1966) The study of fracture of steel, aluminum, and copper under explosive loading. Phys Metal Metallogr Sci (USSR) 24(4):608-615

12. Taylor GI (1934) The mechanism of plastic deformation of crystals. Part 1. Theoretical. Proc R Soc A145:362

13. Kanel GI, Razorenov SV, Fortov VE (2004) Shock-wave phenomena and the properties of condensed matter. Springer, New York

14. Shockey DA, Seaman L, Curran DR (1973) In: Rohde RW, Butcher BM, Holland JR, Karnes CH (eds) Metallurgical effects at high strain rates. Plenum, New York, p 473

15. Meyers MA, Aimone CT (1983) Dynamic fracture (spalling) of metals. Prog Mater Sci 28(1):1-96

16. Farbaniec L, Williams CL, Kecskes L, Ramesh KT, Becker R (2016) Microstructural effects on the spall properties of ECAEprocessed AZ31B magnesium alloy. Int J Impact Eng 98:34-41

17. Farbaniec L, Williams CL, Kecskes L, Becker R, Ramesh KT (2016) Spall response and failure mechanisms associated with a hot-extruded AMX602 Mg alloy (unpublished) 